\title{
Tumour necrosis factor $\alpha$ and nuclear factor $\kappa B$ inhibit transcription of human TFF3 encoding a gastrointestinal healing peptide
}

\author{
M B Loncar, E-d Al-azzeh, P S M Sommer, M Marinovic, K Schmehl, M Kruschewski, \\ N Blin, R Stohwasser, P Gött, T Kayademir
}

Gut 2003;52:1297-1303

See end of article for authors' affiliations

Correspondence to: M B Loncar, Institute of Human Genetics,

Wilhelmstrasse 27 , D-72074 Tübingen, Germany;

mbaus@hotmail.com

Accepted for publication 3 April 2003

\begin{abstract}
Background and aims: Tumour necrosis factor $\alpha(T N F-\alpha)$ induction of nuclear factor $\kappa B(N F \kappa B)$ activation plays a major role in the pathogenesis of inflammatory bowel disease (IBD). Trefoil factor family peptides TFF1, TFF2, and TFF3 exert protective, curative, and tumour suppressive functions in the gastrointestinal tract. In this study, we investigated effects of the TNF- $\alpha / \mathrm{NF} \kappa \mathrm{B}$ regulatory pathway by TNF- $\alpha$ on expression of TFFs.

Methods: After TNF- $\alpha$ stimulation, expression of TFF genes was analysed by quantitative real time polymerase chain reaction and by reporter gene assays in the gastrointestinal tumour cell lines HT-29 and KATO III. Additionally, NFKB subunits and a constitutive repressive form of inhibitory factor $\kappa B$ $(\mid \kappa B)$ were transiently coexpressed. In vivo, morphological changes and expression of TFF3, mucins, and $N F \kappa B$ were monitored by immunohistochemistry in a rat model of 2,4,6-trinitrobenzene sulphonic acid induced colitis.

Results: TNF- $\alpha$ stimulation evoked up to 10-fold reduction of TFF3 expression in the colon tumour cell line HT-29. Downregulation of reporter gene transcription of TFF3 was observed with both TNF- $\alpha$ and $N F \kappa B$, and was reversible by $I_{\kappa B}$. In vivo, the increase in epithelial expression of $N F \kappa B$ coincided with reduced TFF3 expression during the acute phase of experimental colitis.

Conclusions: Downregulation of intestinal trefoil factor TFF3 is caused by repression of transcription through TNF- $\alpha$ and $N F \kappa B$ activation in vitro. In IBD, perpetual activation of $N F \kappa B$ activity may contribute to ulceration and decreased wound healing through reduced TFF3.
\end{abstract}

nflammatory bowel disease (IBD) is represented by two specific gastrointestinal disorders: ulcerative colitis (UC) and Crohn's disease (CD). Pathological processes accompanying IBD are associated with aberrant expression of many proinflammatory cytokines, including tumour necrosis factor $\alpha($ TNF- $\alpha) .{ }^{1}$ Blocking TNF- $\alpha$ by inhibitors ${ }^{2}$ or antibodies is an effective treatment strategy in $\mathrm{CD}^{3}$ Through a downstream signalling pathway, TNF- $\alpha$ triggers degradation of IKB, the inhibitor of nuclear factor $\kappa \mathrm{B}(\mathrm{NF} \kappa \mathrm{B})$ thereby allowing $\mathrm{NF} \kappa \mathrm{B}$ transcription factor to translocate into the nucleus. ${ }^{4}$ Recruitment of this transcription factor results in transcriptional activation of multiple components of the inflammatory response leading to further NFKB activation. ${ }^{5} \mathrm{NF \kappa B}$ is a dimer of variable subunits from NFKB/Rel protein family that to date has five known members: p65, c-Rel, RelB, p50, and p52. The ability of different dimers to recognise slightly different DNA targets increases the ability of NFKB subunits to differentially regulate gene expression. ${ }^{6}$ Blocking the p65 subunit in the 2,4,6-trinitrobenzene sulphonic acid (TNBS) induced mice colitis model abrogates the signs of colitis. ${ }^{7}$ In line with these observations, IBD is generally treated with agents that directly or indirectly inhibit NFKB activation. ${ }^{8}$

In common with immune cells, intestinal epithelial cells also respond to the largely macrophage generated TNF- $\alpha$. This leads to NFKB mediated up or downregulation of some genes $^{9-12}$ involved in the early immune, acute phase, and inflammatory response. Although inhibition of NFKB is a therapeutic concept, it is not known why perpetual activation of NFKB leads to IBD.

The family of trefoil factor (TFF) peptides, with its three members TFF1 (pS2), TFF2 (spasmolytic polypeptide), and TFF3 (intestinal trefoil factor/ITF) represents typical secretory products of mucin producing cells. These small molecules are predominantly expressed in the digestive tract of mammals. Constitutional expression of TFF3 is largely restricted to the goblet cells of the small and large intestine ${ }^{13}{ }^{14}$ whereas TFFl and TFF2 are expressed in the foveolar and glandular cells of the stomach and in Brunner's glands of the duodenum. ${ }^{15} 10$ Although the molecular function of TFF peptides in the gut is not completely understood, evidence from in vitro and in vivo experiments suggests a key role in protecting and curing the gastrointestinal mucosa. ${ }^{17}{ }^{18}$ Oral and systemic application of recombinant TFF peptides promote mucosal defence and wound healing. ${ }^{19-21}$ Mice overexpressing human TFF ${ }^{22}$ or rat $\mathrm{TFF}^{23}$ in the intestine displayed increased resistance to intestinal damage and ulceration. Mice that lack TFF ${ }^{24}$ showed gastric mucosa abnormalities and increased tumorigenesis while mice lacking $\mathrm{TFF}^{25}$ had a higher susceptibility to gut related injury.

As TNF- $\alpha$ and NFKB deregulation is the hallmark of IBD, we investigated whether they affect TFF gene expression. In addition to two well characterised cell lines, we chose a rat model of TNBS induced colitis, simulating features similar to those found in human UC. ${ }^{26} 27$

Our data indicated that in the HT-29 colon cell line, TNF- $\alpha$ through activation of NFKB transcription factor, downregulated the TFF3 gene by transcriptional repression. In the rat

Abbreviations: $C D$, Crohn's disease; FCS, fetal calf serum; GAPDH, glyceraldehyde-3- phosphate dehydrogenase; IBD, inflammatory bowel disease; IL, interleukin; IR, immunoreactivity; ITF, intestinal trefoil peptide; $I_{\kappa B}$, inhibitor of nuclear factor $\kappa B ; N F \kappa B$, nuclear factor $\kappa B ; P A S$, periodic acid-Schiff; PCR, polymerase chain reaction; TFFs, trefoil factors (TFF I, TFF2, TFF3); TNBS, 2,4,6-trinitrobenzene sulphonic acid; TNF- $\alpha$, tumour necrosis factor $\alpha$; UC, ulcerative colitis. 
colitis model, NFkB activation was associated with decreased TFF3 expression in inflamed epithelia.

\section{MATERIALS AND METHODS}

\section{Cell culture, RNA extraction, and reverse transcription}

The gastric adenocarcinoma cell line KATO III was cultivated in Dulbecco's modified Eagle's medium supplemented with $10 \%$ fetal calf serum (FCS). The colon adenocarcinoma cell line HT-29 was cultivated in Waymouth medium with Glutamax and $10 \%$ FCS. ${ }^{28}$ For endogenous TFF expression, cells were seeded in 24 well plates. After 24 hours, cells were incubated in serum free medium and stimulated by addition of $20 \mathrm{ng} / \mathrm{ml}$ TNF- $\alpha$ (Biomol). The effect of TNF- $\alpha$ on expression of TFFs was tested in the range $2.5-40 \mathrm{ng} / \mathrm{ml}$ and was dose responsive. For our experiments, we used the minimal concentration $(20 \mathrm{ng} / \mathrm{ml})$ where TNF- $\alpha$ exerted a significant effect on TFF expression. Total RNA was prepared after 24, 48, 60, and 72 hours using RNA-pure (Peqlab). Isolated RNA was treated with RQI RNase free DNase (Promega) followed by cDNA synthesis using oligo-T15 primer and MMLV reverse transcriptase (Promega).

\section{Real time quantitative PCR}

Polymerase chain reaction (PCR) was performed with SYBR Green on an i-Cycler iQ (Bio-Rad). Cycle conditions were $95^{\circ} \mathrm{C}$, $57^{\circ} \mathrm{C}$, and $72^{\circ} \mathrm{C}$ for 20,40 , and 10 seconds, respectively. Relative quantification values were obtained from the threshold cycle number of three independent experiments measured in triplicate according to the manufacturer's instructions.

The following PCR primers for trefoil peptides and human glyceraldehyde-3-phosphate dehydrogenase (GAPDH) were used:

TFFl-f: 5'-TTTGGAGCAGAGAGGAGGCAATG-3'

TFF 1-r: 5'-ACCACAATTCTGTCTTTCACGGGG-3'

TFF2-f: 5'-CCCATAACAGGACGAACTGC-3'

TFF2-r: $5^{\prime}$-GCACTGATCCGACTCTTGCT-3'

TFF3-f: $5^{\prime}$ - CTTGCTGTCCTCCAGCTCT-3'

TFF3-r: 5'-CCGGTTGTTGCACTCCTT-3'

GAPDH-f: 5'-TGCACCACCAACTGCTTAG-3'

GAPDH-r: 5'-GATGCAGGGATGATGTTC-3'

The effect of TNF- $\alpha$ treatment on GAPDH expression was not significant at any time point, indicating that GAPDH could be used as a stable housekeeping gene in this experiment. ${ }^{29}$

\section{Transient transfection and luciferase assay}

Luciferase reporter plasmid pGL3 (Promega) was used to construct TFF recombinants using the 5'-flanking region of human TFF1 (position -1100 to +38 ), TFF2 (position -821 to +61 ), and TFF3 (position -867 to +63 ), as described previously. ${ }^{28}$ Transient transfection was performed using the cationic polymer transfection reagent ExGen 500 (MBI Fermentas). Six hours after transfection, cells were shifted to serum free medium or serum free medium containing $20 \mathrm{ng} / \mathrm{ml} \mathrm{TNF}-\alpha$ (Biomol). Expression of genes of interest was measured 48 hours later by the Dual-Luciferase Reporter Assay system (Promega). Results were calculated according to the manufacturer's protocol and compared with nonstimulated controls. Each experiment was independently performed a minimum of five times. For cotransfection experiments, $320 \mathrm{ng}$ of the reporter plasmid (containing TFFs promoter) and $96 \mathrm{ng}$ of the following expression plasmids coding for NFKB subunits were used: pMT2T-p50, pMT2T- p65, or CMV-pUHD as control vector. NFKB subunit expression in pMT2T vector is controlled by adenovirus major late promoter and simian virus 40 enhancer. $^{3031}$ A degradation resistant mutant IкB expression plasmid used for specific inhibition of NFKB activity ${ }^{32}$ was obtained from Dr Kube, Tübingen,
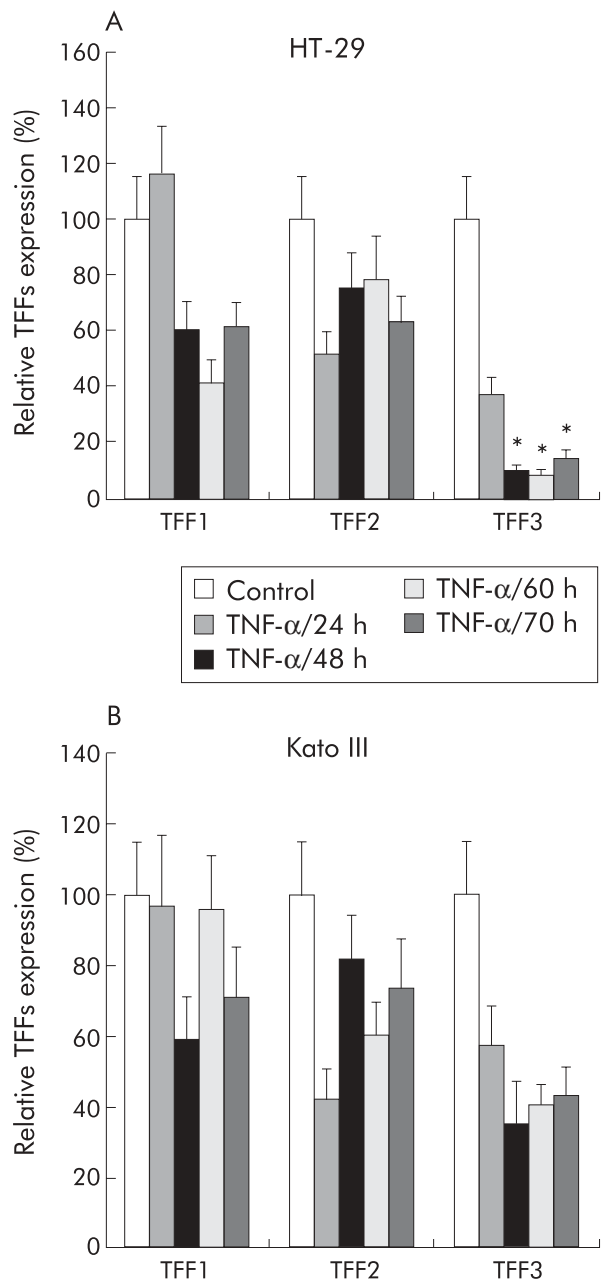

Figure 1 Effect of tumour necrosis factor $\alpha(T N F-\alpha 20 \mathrm{ng} / \mathrm{ml}$ ) on trefoil factor (TFF 1, TFF2, TFF3) mRNA expression, measured by quantitative real time polymerase chain reaction in the intestinal tumour cell line HT-29 (A) and the gastric fumour cell line KATO III (B). TFF expression was measured $24,48,60$, and 72 hours after TNF- $\alpha$ stimulation, and was normalised to glyceraldehyde-3phosphate dehydrogenase (GAPDH) and expressed relative to the appropriate time point of the untreated control (\%). $\Delta c_{\text {, }}$ (threshold cycle) values were determined by subtracting the difference in $c_{t}$ levels between the TFF genes and the GAPDH gene after incubation with TNF- $\alpha$ or with no TNF- $\alpha$ (control) for the indicated times. Remaining TFF expression is calculated by the formula $2^{\text {-(NNFAC-controlact }}$ and expressed relative to the appropriate untreated time point control. *Statistically significant $(99 \%$ confidence interval).

Germany. A luciferase reporter vector carrying six times the consensus binding sequence of NFKB $(6 \times N F \kappa B)$ in the TK minimal promoter was obtained from Dr Schulze-Osthoff, Marburg, Germany.

\section{Statistical analysis}

Data were analysed by one way ANOVA and, if indicated, differences between groups were analysed by appropriate parametric or non-parametric tests with $95 \%$ confidence interval. Data are presented as mean (SD) values of at least three separate experiments.

\section{Rat model of TNBS induced colitis}

The experiment was approved by the local ethics committee. TNBS $20 \mathrm{mg}$ in $0.25 \mathrm{ml}$ of $50 \%$ ethanol were injected following the protocol of Morris and colleagues. ${ }^{26}$ During the experiment, animals had free access to water and food. Six rats were sacrificed on day 0 (control), 4, 11, and 21 after TNBS 


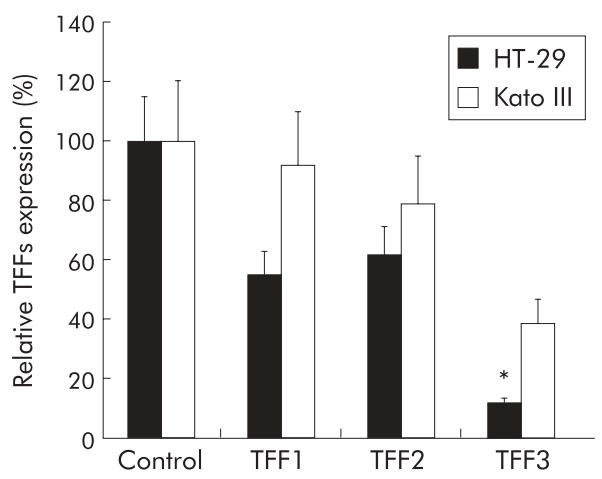

Figure 2 Effect of tumour necrosis factor $\alpha(T N F-\alpha)$ stimulation on trefoil factor (TFF1, TFF2, TFF3) TFF reporter gene expression in the intestinal cell line HT-29 and the gastric cell line KATO III. TFF reporter gene activities 44 hours after TNF- $\alpha(20 \mathrm{ng} / \mathrm{ml})$ stimulation are expressed relative to unstimulated controls. *Statistically significant (95\% confidence interval).

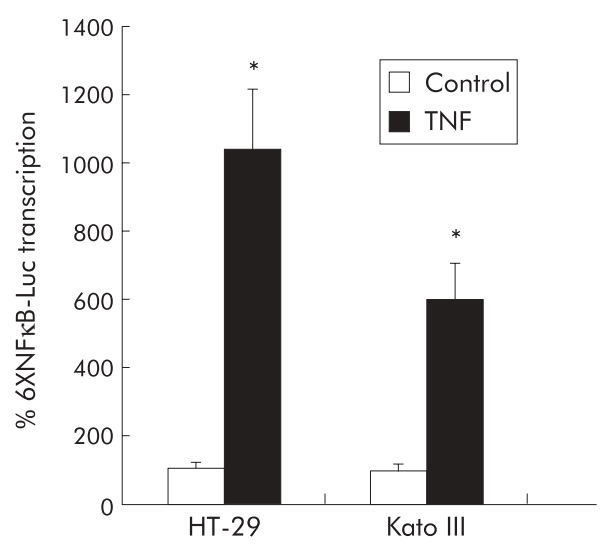

Figure 3 Gene activation of a nuclear factor $\kappa B(N F \kappa B)$ responding reporter gene ( $6 \times N F \kappa B$-Luc) by tumour necrosis factor $\alpha$ (TNF- $\alpha$ ) functionally demonstrates NFKB activation in HT-29 and KATO III cell lines. * Statistically significant $195 \%$ confidence interval).

injection. After autopsy, specimens were taken from the margin area of the treated colon segment. Samples were washed in ice cold phosphate buffered saline, fixed for 24 hours in 5\% paraformaldehyde, and embedded in paraffin wax.

\section{Histology and immunohistochemistry}

Consecutive colon sections $(2 \mu \mathrm{m})$ were stained with haematoxylin-eosin for pathomorphological examination, with periodic acid-Schiff (PAS) for mucins, and with antibodies against TFF3 and the p65 subunit of NFKB. Antigen unmasking for immunohistochemistry was performed by heat treatment $\left(99^{\circ} \mathrm{C}\right)$ for 10 minutes in $10 \mathrm{mM}$ sodium citrate, $\mathrm{pH}$
6. Slides were incubated overnight at $4^{\circ} \mathrm{C}$ in a humid chamber with anti- TFF3 rabbit serum ${ }^{33}$ or with anti-NFKB to detect the activated form of the p65 subunit (Santa Cruz Biotechnology, California, USA). Specific antibody binding was visualised by biotin conjugated sheep antirabbit IgG (Dako), followed by a streptavidin-biotin-horseradish peroxidase complex (Dako) and diaminobenzidine.

Microscopy was done using a light microscope (E-1000, Nikon) with differential interference contrast in combination with a video camera Al13C IR-F (Basler) and a True Colour Analysis System LUCIA 4.60 (Nikon).

\section{RESULTS \\ TNF- $\alpha$ downregulates endogenous TFF3 and TFF3 reporter gene expression}

Following TNF- $\alpha$ induction for $24,48,60$, and 72 hours, quantitative real time PCR revealed a permanent reduction in TFF3 mRNA in the colon cancer line HT-29 (fig 1A). Normalised to the housekeeping gene GAPDH, TNF- $\alpha$ evoked a threefold reduction in TFF3 expression after 24 hours and a 10 -fold reduction after 48 hours in HT-29. After 72 hours, the TFF3 mRNA level began to rise, probably because TNF- $\alpha$, given in a single dose, was either degraded or used up by the cells. TFFI and TFF2 expression were not significantly affected. TNF- $\alpha$ treatment did not influence cell viability, as determined by trypan blue staining.

To determine whether the reduction in TFF mRNA level was due to repression of transcriptional initiation, we used firefly luciferase reporter genes controlled by the $5^{\prime}$ - flanking regions of the corresponding TFF genes. These constructs were previously shown to resemble endogenous TFF gene expression in a variety of gastrointestinal cell lines. ${ }^{28}$ Compared with non-stimulated controls, TNF- $\alpha$ caused downregulation of all three TFF reporter genes in the HT-29 and KATO III cell lines (fig 2). A statistically significant reduction was noted for the TFF3 reporter gene in HT-29 $(8.5 \%)$, suggesting that the observed inhibition of endogenous TFF mRNA (fig 1 ) is due to repression of transcriptional initiation.

To prove that TNF- $\alpha$ mediates activation of NFKB, we transfected cells with a vector containing $6 \times \mathrm{NFKB}$ binding sites in a promoter controlling expression of firefly luciferase reporter gene (fig 3). Indeed, TNF- $\alpha$ stimulated its transcription ( 11 -fold in HT-29, sixfold in KATO III), indicating a functional TNF- $\alpha$ inducible NFKB signalling pathway in both cell lines. These results, as well as the fact that NFKB is a key player in signalling inflammatory processes and governing the immune response, led to a detailed investigation of this transcription factor. A search in the Transfac 4.0 database for putative NFKB binding sites revealed several motifs in the $5^{\prime}$-flanking region of all three human TFF genes (table 1) sharing 70-90\% identity to the consensus NFKB binding site.

\section{Transiently expressed NFKB (p50/p65) affects TFF3 expression}

To demonstrate that NFKB transcription factor is indeed responsible for TFF3 downregulation, we transfected the

\begin{tabular}{|c|c|c|c|c|c|}
\hline \multicolumn{2}{|c|}{ TFF1 promoter } & \multicolumn{2}{|c|}{ TFF2 promoter } & \multicolumn{2}{|c|}{ TFF3 promoter } \\
\hline Position & Identity (\%) & Position & Identity (\%) & Position & Identity (\%) \\
\hline $\begin{array}{r}-93 \\
-231 \\
-284 \\
-609 \\
-735 \\
-890\end{array}$ & $\begin{array}{l}90 \\
90 \\
90 \\
90 \\
90 \\
90\end{array}$ & $\begin{array}{l}-257 \\
-297 \\
-421 \\
-541 \\
-655\end{array}$ & $\begin{array}{l}80 \\
80 \\
90 \\
80 \\
80\end{array}$ & $\begin{array}{r}-97 \\
-226 \\
-382 \\
-644 \\
-811\end{array}$ & $\begin{array}{l}80 \\
80 \\
80 \\
80 \\
70\end{array}$ \\
\hline
\end{tabular}




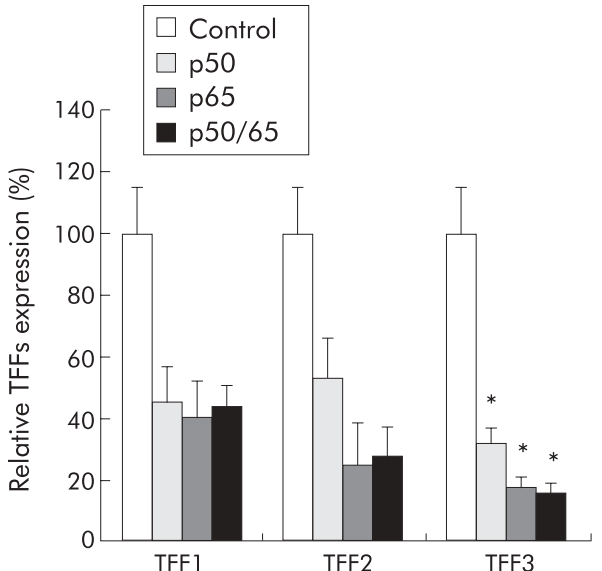

Figure 4 Transient nuclear factor $\kappa B(N F \kappa B)$ expression affects trefoil factor TFF3 transcription. Cotransfection of plasmids constitutively expressing NFKB subunits $p 50, p 65$, and $p 50 / 65$ downregulated expression of the TFF3 reporter gene in the HT-29 cell line. TFF reporter gene activity was expressed relative to controls transfected with TFF reporter plasmid and empty PUHD vector. * Statistically significant (95\% confidence interval).

HT-29 cell line with plasmids overexpressing NFKB subunits p50 and p65, separately and in combination. These subunits can dimerise with each other or with other members of the $\mathrm{NFKB} /$ Rel protein family already present in cells, translocate to the nucleus, and affect gene transcription. Reporter plasmids carrying TFF gene promoters were cotransfected with expression vectors encoding the NFKB subunits. TFF3 expression was significantly reduced on overexpression of the p50 and p65 subunits, and by a combination of both subunits (fig 4). It is interesting to note that cotransfection of p50 and p65 NFKB subunits had a greater, but not significant, downregulating effect on TFF1 and TFF2 expression in comparison with TNF- 0 stimulation, probably because overexpressed NFKB subunits are more effective than TNF- $\alpha$ alone.

\section{I $\kappa$ B neutralised NF $\kappa B$ mediated TFF3 repression}

To prove that TFF3 downregulation is due to NFKB activation, we inhibited NFKB activation using its specific inhibitor IКB. We used a constitutive repressive form of IкB, also called super-repressor, that resists proteolytic degradation. ${ }^{32}$ We verified that the IKB expression vector inhibits activation of NFKB responding reporter gene (fig $5 \mathrm{~A}$ ). To test the efficiency of constitutively expressed IKB, $6 \times \mathrm{NF}$ KB-luc reporter plasmid was transiently cotransfected with or without IKB expression vector and stimulated with TNF- $\alpha$ to induce the NFkB pathway. NFKB activation by TNF- $\alpha$ resulted in pronounced transcription of a NFKB responding reporter gene. Its stimulation by TNF- $\alpha$ was abrogated in the presence of IKB, strongly indicating that in the HT-29 cell line TNF- $\alpha$ acts through the NFKB signalling pathway and that this effect can be neutralised by IкB.

To test the effect of NFאB inhibition on TFF3 expression, HT-29 cells were cotransfected with TFF3 reporter plasmid and different plasmids constitutively expressing the NFKB subunits (p50, p65, p50/p65). In addition, to inhibit NFKB plasmid expressing IкB was added (fig 5B). Cotransfection with the NFKB subunits showed significant downregulation of TFF3 expression (fig 5B). After transient expression of IкB together with p50, p65, and p50/65, TFF3 downregulation was neutralised. With this experiment we confirmed that TFF3 downregulation is controlled by NFKB transcription factor.

\section{Association of TFF3 repression with NFKB recruitment in experimental colitis}

The TNBS hapten induces focal inflammation, oedema, and ulceration accompanied by loss of the typical epithelial structure, decreased number of goblet cells, and infiltration of immune cells. ${ }^{26}{ }^{27}$ After rapid development of inflammation with complete loss of parts of the treated mucosa (days 2-4), complete regeneration occurs over the next 15-20 days. In normal colonic tissue (fig 6A-C), all mucin carrying cells of the upper two thirds of the crypt (fig 6B) exhibited distinct TFF3 immunoreactivity (IR) (fig 6A) whereas expression of activated NFKB was confined to a few cells of the lamina propria (fig 6C).

Four days after TNBS administration (fig 6D-F), lesions of variable severity were found in all animals. Irregular crypts displayed a reduction in the number of goblet cells, especially in the upper third and at the surface. Weak TFF3 IR was detectable in a small fraction of the remaining goblet cells at the luminal surface (fig 6D). Activated NFKB was expressed in macrophages and in other stromal cells, and in a number of epithelial cells, mainly in the middle and upper third of the crypts (fig 6F).
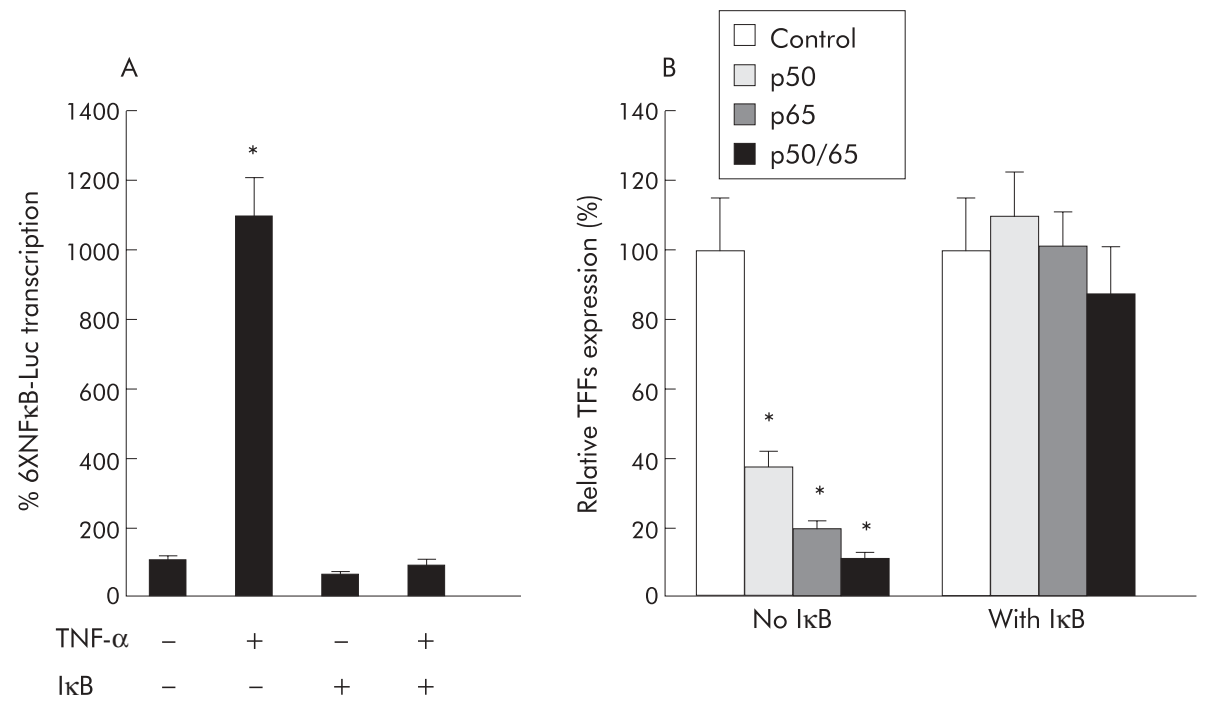

Figure 5 Specific nuclear factor $\kappa B(N F \kappa B)$ inhibitor $I \kappa B$ abrogates $N F \kappa B$ mediated downregulation of trefoil factor TFF3 in the HT-29 cell line. (A) Tumour necrosis factor $\alpha$ (TNF- $\alpha$ ) significantly (*) stimulated transcription of the NFKB responsive $6 \times N F \kappa B$-luc reporter gene. Cotransfection of plasmid constitutively expressing the NFKB inhibitor IKB inhibited TNF- $\alpha$ induced $6 \times N F$ FB-luc responsive gene expression. (B) Transient expression of NFKB subunits (p50, p65,p50/p65) significantly $\left(^{*}\right)$ reduced TFF3 reporter gene expression. Coexpression of a plasmid constitutively expressing the NFKB inhibitor I $K B$ neutralised TFF3 downregulation induced by expression of the NFKB subunits. 

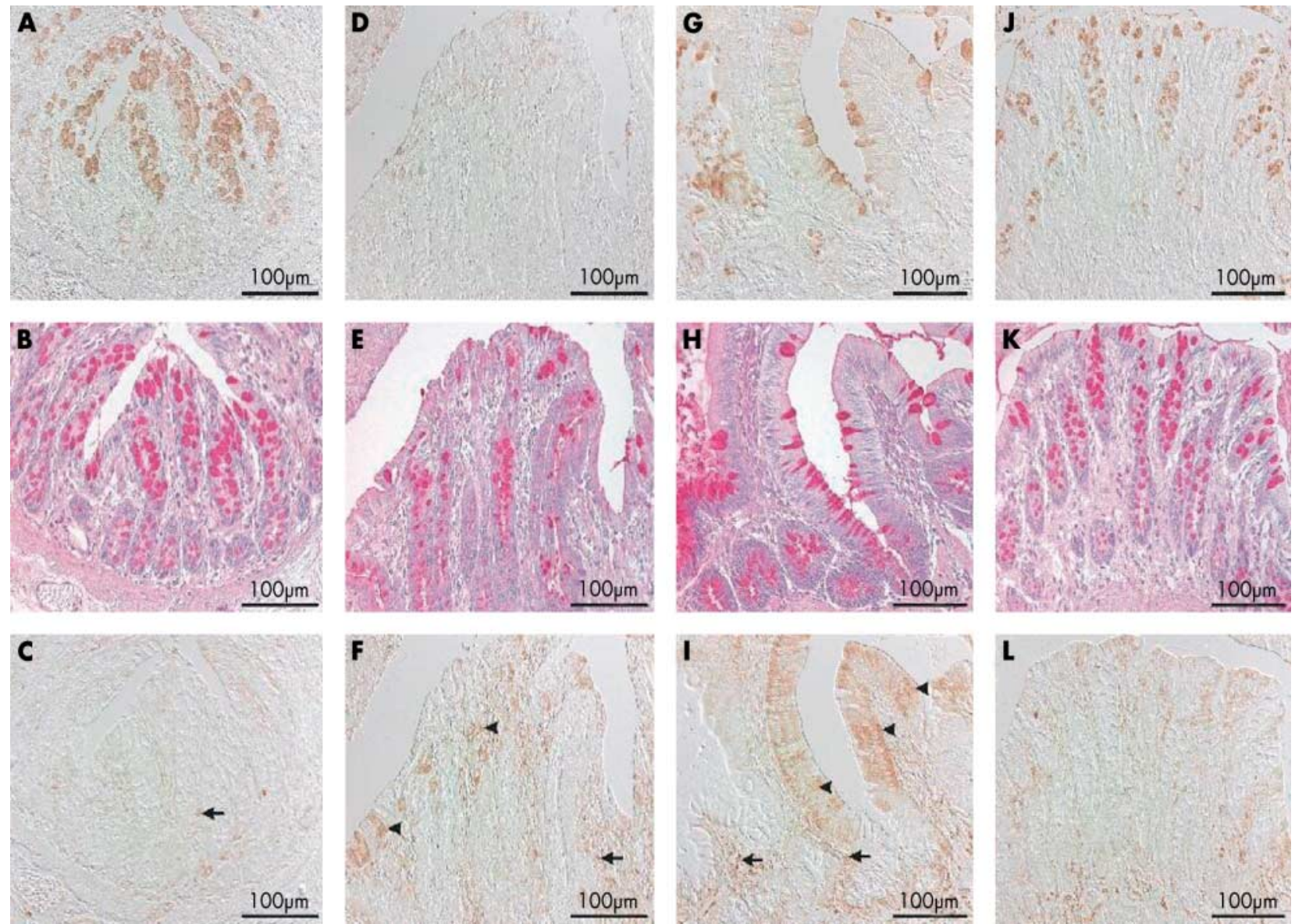

Figure 6 Immunoreactivity (IR) of trefoil factor TFF3 (A, D, G, J), nuclear factor $\kappa B(N F \kappa B)$ p65 (C, $F, I$, L), and periodic acid-Schiff (PAS) staining for mucins $(B, E, H, K)$ in a rat model of experimental colitis. (A-C) 2,4,6-Trinitrobenzene sulphonic acid (TNBS) induction, day 0 (control): the intact colonic mucosa displays arrayed crypts with regularly distributed goblet cells with normal mucin production (B) and pronounced TFF3 staining in (A) in the upper two thirds of the crypt. NFKB (C) is confined to the stroma cells of the lamina propria (arrow). (D-F) TNBS induction, day 4: serious damage to the colonic epithelium is associated with a lower number of goblet cells and mucin production (E). Weak TFF3 staining is restricted to a few goblet cells of the surface mucosa (D). NFKB staining (F) is pronounced in the infiltrating cells of the lamina propria (arrow) and in some epithelial cells (arrowheads). (G-I) TNBS induction, day 11: the distribution of the goblet cells as well as PAS staining (H) is irregular but increased compared with the acute inflammation state (E). TFF3 (G) staining is still reduced in many of the PAS positive goblet cells. NFKB (I) is present in the infiltrating cells (arrows) as well as in the crypt luminal epithelium (arrowheads), especially in areas with both low TFF3 IR and a low number of goblet cells. (J-L) TNBS induction, day 21 : epithelial and goblet cells are regularly distributed and mucin production is restored (K). TFF3 (J) expression pattern has also recovered and is detectable in almost the same intensity as in control samples (A). NFKB (L) is barely detectable in the epithelium.

On day 11 (fig 6G-I), crypt branching indicated the beginning of recovery. The resulting irregular mucosal architecture was associated with an overall increase in the number of goblet cells compared with day 4 (fig 6H). Also, the start of recovery of TFF3 expression in a fraction of goblet cells of the crypt was noted (fig 6G). NFKB was strongly expressed in both epithelial cells and infiltrated lymphocytes. Interestingly, localisation of NFKB in the epithelium was predominantly detected in regions of low TFF3 and mucin expression (fig 6I).

On day 21 (fig 6J-L), the mucosal architecture was completely rebuilt with regularly sized and distributed crypts. The healing process was associated with an increase in PAS positive mucin producing cells (fig 6K) and recovery of TFF3 peptide in goblet cells (fig 6J), reaching levels found in control animals. Recovery of the normal epithelial architecture was accompanied by a strong reduction in NFKB expression in both epithelial and stromal cells (fig 6L). Taken together, these results suggest $\mathrm{NF} \kappa \mathrm{B}$ recruitment in association with a strong reduction in TFF3 expression during the acute phase of colitis.

\section{DISCUSSION}

Several lines of evidence imply that cytokine (TNF- $\alpha$ and interleukin (IL)-1) induction leading to NFKB activation plays a major role in the pathogenesis of IBD. Antibodies against TNF- $\alpha$ and inhibitors of its production are currently widely used drugs in IBD. $^{3}$ In addition, drugs that directly or indirectly inhibit $\mathrm{NF \kappa B}$ are promising therapeutic tools in IBD. ${ }^{34-36}$ Sulphasalazine, one of the most effective agents for IBD, inhibits TNF- $\alpha$ induced NFKB activation via inhibition of IKB phosphorylation. ${ }^{8}$

Trefoil peptides play an important role in maintenance of epithelial integrity, protection, and wound healing. ${ }^{20}{ }^{37}$ During experimental mucositis, the temporal change in TFF3 mRNA is associated with the commitment of the epithelial cells to differentiate into goblet cells. ${ }^{38}$ Moreover, intestinal trefoil factor (TFF3) confers colonic epithelial resistance to apoptosis and stimulates cell migration. ${ }^{21}{ }^{39}$ Finally, several reports show that both luminal and systemic application of recombinant TFF peptides as well as overexpression of transgenic TFF3 promote mucosal defence and heal experimental colitis. ${ }^{23} 254041$

In the present study, we demonstrated that TNF- $\alpha$ induced downregulation of TFF 3 transcription is mediated by NFKB. The strong reduction of TFF3 peptide expression in a rat model of colitis was associated with inflammation and NFKB recruitment. These results are consistent with many reports demonstrating NFKB signalling in gastrointestinal epithelia. ${ }^{45}$ A 
relatively late effect on TFF3 expression (44-48 hours after TNF- $\alpha$ stimulation) indicates a possible indirect effect of NFKB activation on TFF3 expression. Recently, we showed that TFF3 downregulation also occurs on stimulation of HT-29 with IL- $1 \beta$, another strong activator of NFKB..$^{42}$

Although for simplicity NFKB is often referred to as if it were a single entity, in reality it is a complex mixture of homoand heterodimers all with distinct characteristics and biological properties. ${ }^{43}$ These homo- or heterodimeric complexes vary in their DNA binding specificity and as such can differentially regulate gene expression. NFKB exists in the cytoplasm in an inactive form by virtue of its association with a class of inhibi-

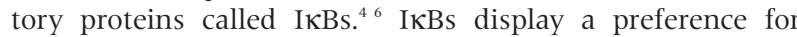
specific NFKB complexes. Each IKB has the potential to participate in distinct regulatory pathways affecting activation of different NFKB complexes and at the end can influence transcription of different genes. The existence of a multigene family of NFKB proteins and a multigene family of IKB proteins, together with possible post- translational modifications could, in part, account for the complex regulatory potential displayed by NFKB. ${ }^{44}$ Additionally, it is known that NFKB can interact with other transcription factors such as AP- 1 and C/EBP. Both factors belong to the bZIP class of DNA binding proteins characterised by leucine zipper structure and adjacent basic DNA binding domain. The bZIP region has been reported to directly interact with the Rel homology domain of NFKB. ${ }^{45}{ }^{46}$ Putative AP-1 and C/EBP binding sites are located within the $5^{\prime}$-flanking region of all TFF genes. ${ }^{42}$ Alternatively, binding of NFKB may compete with the binding of NF-1 for interaction with a coactivator such as $\mathrm{p} 300 / \mathrm{CBP}{ }^{9}$

Many putative binding sites of NFKB are present in the upstream region of all three human TFF genes. In the TFF3 promoter, four putative NFKB binding sites displaying $80 \%$ identity (two mismatches) to the consensus site were found (table 1). Mutating these putative NFKB binding sites would be necessary to discover which is responsible for NFKB binding and thus regulation of TFF3 expression. In addition, binding of NFKB to chromatin in vivo would give a more realistic picture than demonstrating in vitro binding to double stranded oligonucleotides by EMSA. A NFKB binding site with two mismatches was reported to downregulate human papilloma virus HPVl6 gene expression although the affinity of NFKB for this site was 250 -fold lower compared with affinity for the consensus NFKB binding site.? The discrepancy between in vitro and in vivo DNA binding has also been observed with other transcription factors, including c-Myc. ${ }^{47}$

Although NFKB is largely considered to be a transcriptional activator of a variety of genes involved in early immune, acute phase, and inflammatory responses, ${ }^{31}$ it can also directly repress transcription of some genes. ${ }^{9-11} 4849$ The background of repression has still to be elucidated.

Taken together, our in vitro data suggest downregulation of TFF3 expression in HT-29 as a consequence of NFKB activation by TNF- $\alpha$, and our in vivo data confirm reduced TFF3 expression in the rat model of colitis. Bearing in mind that TFF3 promotes mucosal defence, it is intriguing to ask whether its strong reduced expression may in vivo causally contribute to epithelial dismorphology and ulceration.

In a rat model of TNBS induced colitis, we demonstrated that NFKB expression in both immune and epithelial cells paralleled a marked reduction in TFF3 expression (fig 6). Consistent with our data, Xian and colleagues ${ }^{38}$ showed that TFF3 expression in the intestine is decreased in methotrexate induced damage. Itoh and colleagues $^{50}$ also reported a decrease in TFF3 production during the early stage ( $1-4$ days after induction) of experimentally induced ulcerative damage with TFF3 upregulation during the recovery phase. Tran and colleagues ${ }^{20}$ showed that TFF3 expression is unaltered during hapten/ethanol induced colitis in the rat, suggesting that inflammatory and ulcerogenic influences counteract each other. We observed a similar time course of marked depletion of TFF3 production associated with a reduction in the number of goblet cells. Our time course measurements suggested that TFF3 reduction may be an early event in TNBS induced colitis. Clearly, the observed reduction in the number of goblet cells did not fully account for the strong reduction in TFF3 expression as we noticed mucin producing cells with decreased and with no TFF3 immunoreactivity on days 4 and 11 . Therefore, the strong reduction in TFF3 expression during the acute phase of experimental colitis might provoke cellular changes already attributed to TFF3, such as redifferentiation, apoptosis, decrease in cell migration, and decreased barrier function, ${ }^{51}$ all of which may eventually contribute to ulceration.

However, in an apparent contradiction to our results, upregulation of trefoil peptides was observed in an ulcer associated cell lineage $\mathrm{e}^{52-55}$ and in an experimental rat model. ${ }^{56}$ In the latter, a cryoprobe was used to damage the rat stomach, and TFF 2 and TFF 3 mRNA were upregulated in discrete cells of the regenerating glands at the ulcer margin. This damage may not reflect the actual situation during TNBS induced colitis. More likely, the observed upregulation of TFF2 and TFF3 may be part of the acute phase response to cope with the harsh damage, necrosis, and threat of epithelial integrity in the stomach. In gastric and intestinal cell lines, we found that osmotic forces, ethanol, as well as acute phase gene regulators HNF-3 and GATA- 6 induced upregulation of TFF genes. ${ }^{57-59}$ Recently it was reported that duodenal TFF3 expression was low in association with chronic inflammation and villus atrophy in coeliac disease patients, and that recovery following removal of gluten from the diet was accompanied by recovery in TFF3 expression..$^{60}$ In humans, upregulation of trefoil genes TFF1 and TFF2 but not TFF3 was observed in IBD. ${ }^{52}$ As TFF1 and TFF 2 are not expressed under normal conditions in the intestine (except in Brunner's gland of the duodenum), their upregulation could be easily detected and has been initially noted in cancer and in patients with IBD. ${ }^{61}$ Later, TFFI and TFF2 upregulation was confined to the ulcer associated cell lineage, restricted to the nearby mucosa of the duodenal ulcers. $^{525}$ Our in vitro and in vivo data imply that TNF- $\alpha$ causes NFKB mediated transcriptional repression of the TFF3 gene and thereby reduces the steady state level of this peptide. This regulatory mechanism may partially explain the impairment of wound healing in IBD. Further studies are required to address the biological implications of TFF3 downregulation in vivo. Activation of TFF genes may eventually generate opportunities for treatment of gastrointestinal diseases.

\section{ACKNOWLEDGEMENTS}

Supported by the Deutsche Krebshilfe (10-1547Gö-2) and the BMBF (IZKF Fö 01KS9602) to PG and NB. We thank P Fegert, W Kornberger, and E Meyer for excellent technical assistance, and D Kube, HJ Buhr, G Jacobasch, and G Stamp for helpful suggestions.

\section{Authors' affiliations}

M B Loncar*, E-d Al-azzeh*, N Blin, P Gött, T Kayademir, Division of Molecular Genetics, University of Tübingen, Wilhelmstr 27, 72074 Tübingen, Germany

P S M Sommer, Federal University of Rio Grande do Norte, DBG, 56078-970, RN, Brazil

M Marinovic, K Schmehl, R Stohwasser, German Institute of Human Nutrition, Arthur-Scheunert-Allee 114-116, 14558 Bergholz- Rehbrücke, Germany

M Kruschewski, Free University of Berlin, Benjamin Franklin Medical Centre, Surgical Clinic I, 12200 Berlin, Germany

*M B Loncar and E-d Al-azzeh contributed equally to this work.

\section{REFERENCES}

1 Beutler B, Cerami A. Tumor necrosis, cachexia, shock, and inflammation: a common mediator. Annu Rev Biochem 1988;57:505-18 
2 Armstrong AM, Foulkes $R$, Jennings $G$, et al. Tumour necrosis factor inhibitors reduce the acute-phase response in hapten-induced colitis. $\mathrm{Br}$ Surg 2001; 88:235-40.

3 Baert FJ, Rutgeerts PJ. Medical therapies for ulcerative colitis and Crohn's disease. Curr Gastroenterol Rep 2000;2:446-50.

4 Ghosh S, May M, Kopp EB. NF-kappa B and Rel proteins: evolutionarily conserved mediators of immune responses. Annu Rev Immunol 1998;16:225-60.

5 Schmid RM, Adler G. NF-kB/Rel/lkB: Implications in gastrointestinal diseases. Gastroenterology 2000;1 18:1208-28

6 Baldwin AS.The NFkb and IkB proteins: New discoveries and Insights Annu Rev Immunol 1996;14:649-81.

7 Neurath MF, Pettersson S, Zum Büschenfelde, et al. Local administration of antisense phosphorothioate oligonucleotides to the p 65 subunit of NF-kappaB abrogates established experimental colitis in mice. Nat Med 1996;2:998-1004

8 Wahl C, Liptay S, Adler G, et al. Sulfasalazine: a potent and specific inhibitor of nuclear factor kappa B. J Clin Invest 1998;101:1163-74.

9 Fontaine V, van der Meijden E, de Graaf J, et al. A functional NF-kappaB binding site in the human papillomavirus type 16 long control region. Virology 2000;272:40-9.

10 Wissink S, van Heerde EC, Schmitz ML, et al. Distinct domains of the RelA NF-kappaB subunit are required for negative cross-talk and direct interaction with the glucocorticoid receptor. J Biol Chem 1997:272:22278-84

11 Supakar PC, Jung MH, Song CS, et al. Nuclear factor kappa B functions as a negative regulator for the rat androgen receptor gene and NF-kappa B activity increases during the age- dependent desensitization of the liver. J Biol Chem 1995;270:837-42.

12 Murakami S, Lefebvre V, de Crombrugghe B. Potent inhibition of the master chondrgenic factor Sox 9 gene by interleukin-1 and tumor necrosis factor-alpha. J Biol Chem 2000; 275:3687-92

13 Podolsky DK, Lynch Devaney K, Stow JL, et al. Identification of human intestinal trefoil factor. Goblet cell- specific expression of a peptide targeted for apical secretion (published erratum appears in J Biol Chem 1993;268: 12230). J Biol Chem 1993;268:6694-702

14 Hauser F, Poulsom R, Chinery R, et al. hPl.B, a human P-domain peptide homologous with rat intestinal trefoil factor, is expressed also in the ulcer-associated cell lineage and the uterus. Proc Natl Acad Sci U S A 1993;90:6961-5.

15 Rio MC, Bellocq JP, Daniel JY, et al. Breast cancer-associated pS2 protein: synthesis and secretion by normal stomach mucosa. Science 1988;241:705-8

16 Tomasetto C, Rio MC, Gautier C, et al. hSP, the domain-duplicated homolog of pS2 protein, is co- expressed with pS2 in stomach but not in breast carcinoma. EMBO J 1990:9:407-14.

17 Podolsky DK. Mechanisms of regulatory peptide action in the gastrointestinal tract: trefoil peptides. J Gastroenterol 2000;35(suppl 12):69-74

18 Thim L. Trefoil peptides: from structure to function. Cell Mol Life Sci 1997;53:888-903.

19 Babyatsky MW, DeBeaumont M, Thim L, et al. Oral trefoil peptides protect against ethanol- and indomethacin- induced gastric injury in rats. Gastroenterology 1996:110:489-97.

20 Tran CP, Cook GA, Yeomans ND, et al. Trefoil peptide TFF2 (spasmolytic polypeptide) potently accelerates healing and reduces inflammation in a rat model of colitis. Gut 1999;44:636-42.

21 Taupin DR, Kinoshita K, Podolsky DK. Intestinal trefoil factor confers colonic epithelial resistance to apoptosis. Proc Natl Acad Sci U S A 2000;97:799-804.

22 Playford RJ, Marchbank T, Goodlad RA, et al. Transgenic mice that overexpress the human trefoil peptide pS2 have an increased resistance to intestinal damage. Proc Natl Acad Sci U S A 1996;93:2137-42.

23 Marchbank T, Cox HM, Goodlad RA, et al. Effect of ectopic expression of rat trefoil factor family 3 (rTFF3, intestinal trefoil factor) in the jeunum of transgenic mice. J Biol Chem 2001;26:24008-96.

24 Lefebvre O, Chenard MP, Masson R, et al. Gastric mucosa abnormalities and tumorigenesis in mice lacking the pS2 trefoil protein. Science 1996:274:259-62

25 Mashimo H, Wu DC, Podolsky DK, et al. Impaired defense of intestinal mucosa in mice lacking intestinal trefoil factor. Science mucosa in mice lackin

26 Morris GP, Beck PL, Herridge MS, et al. Hapten-induced model of chronic inflammation and ulceration in the rat colon. Gastroenterology 1989;96:795-803.

27 Schmehl K, Florian S, Jacobasch G, et al. Deficiency of epithelial basement membrane laminin in ulcerative colitis affected human colonic mucosa. Int I Colorectal Dis 2000:15:39-48.

28 Beck S, Sommer P, Blin N et al. 5'-flanking motifs control cell specific expression of trefoil factor genes (TFF). Int J Mol Med 1998;2:353-61.

29 Schmittgen TD, Zakrajsek BA Effect of experimental treatment on housekeeping gene expression: validation by real-time, quantitative RT-PCR. J Biochem Biophys Methods 2000;46:69-81.

30 Bours V, Burd PR, Brown K, et al. A novel mitogen-inducible gene product related to $\mathrm{p} 50 / \mathrm{p} 105-\mathrm{NF}-$ kappa $B$ participates in transactivation through a kappa B site. Mol Cell Biol 1992;12:685-95.

31 Desbarats L, Gaubatz S, Eilers M. Discrimination between different E-box-binding proteins at an endogenous target gene of c-myc. Genes Dev 1996:10:447-60.

32 Henkel T, Zabel U, van Zee K, et al. Intramolecular masking of the nuclear location signal and dimerization domain in the precursor for the p50 NF-kappa B subunit. Cell 1992;68:1121-33.
33 Dos Santos Silva E, Ulrich M, Döring G, et al. Trefoil factor family-domain peptides in the human respiratory tract. J Pathol 2000; 190: 133-42

34 Jobin C, Sartor RB. The lkappaB/NF-kappaB system: a key determinant of mucosal inflammation and protection. Am J Physiol Cell Physiol 2000;278:C451-62.

35 Kaiser GC, Yan F, Polk DB. Mesalamine blocks tumor necrosis factor growth inhibition and nuclear factor kappa B activation in mouse colonocytes. Gastroenterology 1999;1 16:602-9.

36 Segain JP, Raingeard dIB, Bourreille A, et al. Butyrate inhibits inflammatory responses through NFkappaB inhibition: implications for Crohn's disease. Gut 2000:47:397-403.

37 Otto WR, Patel K. Trefoil factor family (TFF)-domain peptides in the mouse: embryonic gastrointestinal expression and wounding response. Anat Embryol 1999;199:499-508

38 Xian CJ, Howarth GS, Mardell CE, et al. Temporal changes in TFF3 expression and jejunal morphology during methotrexate-induced damage and repair. Am J Physiol 1999:277:G785-95.

39 Kinoshita K, Taupin DR, Itoh $\mathrm{H}$, et al. Distinct pathways of cell migration and antiapoptotic response to epithelial injury: structure-function analysis of human intestinal trefoil factor. Mol Cell Biol 2000;20:4680-90.

40 Playford RJ, Marchbank T, Chinery R, et al. Human spasmolytic polypeptide is a cytoprotective agent that stimulates cell migration. Gastroenterology 1995;108:108-16.

41 Kindon H, Pothoulakis C, Thim L, et al. Trefoil peptide protection of intestinal epithelial barrier function: cooperative interaction with mucin glycoprotein. Gastroenterology 1995;109:516-23.

42 Dossinger V, Kayademir T, Blin N, et al. Down-regulation of TFF Expression in Gastrointestinal Cell Lines by Cytokines and Nuclear Factors. Cell Physiol Biochem 2002;12:197-206.

43 Perkins ND. Achieving Transcriptional Specificity with NF- $\kappa B$. Int J Biochem Cell Biol 1997;29:1433-48.

44 Mercurio F, Manning AM. NF- $\mathrm{kB}$ as primary regulator of the stress response. Oncogene 1999;18:6163-71.

45 LeClair KP, Blanar MA, Sharp PA. The p50 subunit of NF-kappa B associates with the NF-IL6 transcription factor. Proc Natl Acad Sci U S A 1992:89:8145-9.

46 Stein B, Cogswell PC, Baldwin AS Jr. Functional and physical associations between NF- kappa B and C/EBP family members: a Rel domain-bZIP interaction. Mol Cell Biol 1993;13:3964-74.

47 Boyd KE, Wells J, Gutman J, et al. c-Myc target gene specificity is determined by a post- DNA-binding mechanism. Proc Natl Acad Sci U S A 1998;95:13887-92.

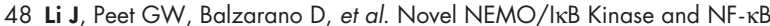
Target Genes at the Pre-B to Immature B Cell Transition. J Biol Chem 2001;276:18579-90

49 Xiang Li, Massa PM, Adedayo $\mathrm{H}$, et al. IKK $\alpha$, IKK $\beta$, and NEMO/IKK $\gamma$ are each required for the NF- $\mathrm{KB}$-mediated inflammatory response program. J Biol Chem 2002;277:45129-40.

50 Itoh $\mathbf{H}$, Tomita $M$, Uchino $H$, et al. cDNA cloning of rat pS2 peptide and expression of trefoil peptides in acetic acid-induced colitis. Biochem J 1996;318:939-44

51 Hoffmann W, Jagla W, Wiede A. moleculare medicine of TFF-peptides: From gut to brain. Histol Histopathol 2001:16:319-34

52 Wright NA, Poulsom R, Stamp G, et al. Trefoil peptide gene expression in gastrointestinal epithelial cells in inflammatory bowel disease. Scand J Gastroenterol Suppl 1992;193:76-82.

53 Poulsom R, Chinery R, Sarraf C, et al. Trefoil peptide gene expression in small intestinal Crohn's disease and dietary adaptation. J Clin Gastroenterol 1993;17(suppl 1):S78-91.

54 Ahnen DJ, Poulsom R, Stamp GW, et al. The ulceration-associated cell lineage (UACL) reiterates the Brunner's gland differentiation programme but acquires the proliferative organization of the gastric gland. J Pathol 1994; 173:317-26

55 Khulusi S, Hanby AM, Marrero JM, et al. Expression of trefoil peptides pS2 and human spasmolytic polypeptide in gastric metaplasia at the margin of duodenal ulcers. Gut 1995; 37:205-9.

56 Alison MR, Chinery R, Poulsom R, et al. Experimental ulceration leads to sequential expression of spasmolytic polypeptide, intestinal trefoil factor, epidermal growth factor and transforming growth factor alpha mRNAs in rat stomach. J Pathol 1995:175:405-14.

57 Lüdeking A, Fegert $P$, Blin $N$, et al. Osmotic changes and ethano modify TFF gene expression in gastrointestinal cell lines. FEBS Lett 1998;439:180-4

58 Beck S, Sommer P, Dos Santos Silva E, et al. Hepatocyte nuclear factor 3 (winged helix domain) activates trefoil factor gene TFF1 through a binding motif adjacent to the TATAA box. DNA Cell Biol $1999 \cdot 18: 157-64$

59 Al-azzeh E, Fegert $\mathrm{P}, \mathrm{Blin} \mathrm{N}$, et al. Transcription factor GATA-6 activates expression of gastroprotective trefoil genes TFF1 and TFF2. Biochim Biophys Acta 2000; 1490:324-32.

60 Ciacci C, Di Vizio D, Seth R, et al. Selective reduction of intestinal trefoil factor in untreated coeliac disease. Clin Exp Immunol 2002;130:52631.

61 Rio MC, Chenard MP, Wolf C, et al. Induction of pS2 and hSP genes as markers of mucosal ulceration of the digestive tract. Gastroenterology $1991 ; 100: 375-9$ 